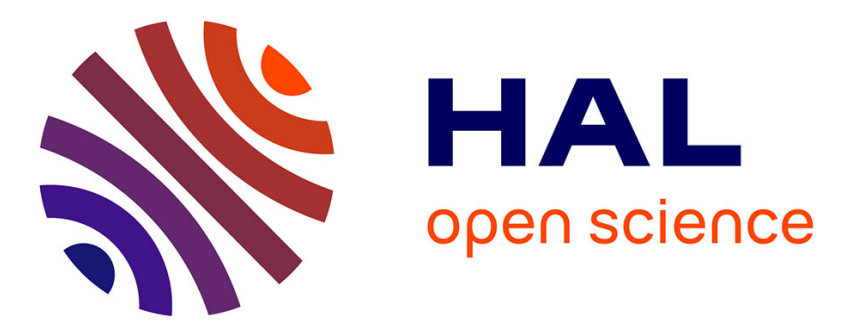

\title{
A DSM Clustering Method for Product and Service Modularization
}

Omar Ezzat, Khaled Medini, Maria Stoettrup Schioenning Larsen, Xavier Boucher, Thomas Ditlev Brunoe, Kjeld Nielsen, Xavier Delorme

\section{- To cite this version:}

Omar Ezzat, Khaled Medini, Maria Stoettrup Schioenning Larsen, Xavier Boucher, Thomas Ditlev Brunoe, et al.. A DSM Clustering Method for Product and Service Modularization. IFIP International Conference on Advances in Production Management Systems (APMS), Sep 2019, Austin, TX, United States. pp.375-382, 10.1007/978-3-030-30000-5_47 . emse-02278666

\section{HAL Id: emse-02278666 \\ https://hal-emse.ccsd.cnrs.fr/emse-02278666}

Submitted on 24 Jan 2020

HAL is a multi-disciplinary open access archive for the deposit and dissemination of scientific research documents, whether they are published or not. The documents may come from teaching and research institutions in France or abroad, or from public or private research centers.
L'archive ouverte pluridisciplinaire HAL, est destinée au dépôt et à la diffusion de documents scientifiques de niveau recherche, publiés ou non, émanant des établissements d'enseignement et de recherche français ou étrangers, des laboratoires publics ou privés.

\section{(c)(1)}

Distributed under a Creative Commons Attribution| 4.0 International License 


\title{
A DSM clustering method for product and service modularization
}

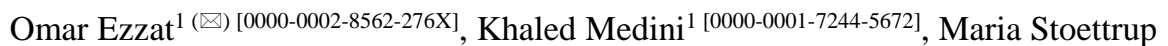 \\ Schioenning Larsen ${ }^{[0000-0003-3396-4925]}$, Xavier Boucher ${ }^{\text {[0000-0002-0869-4153] }}$, Thomas D. \\ Brunoe $^{2 ~[0000-0002-9847-6562]}$, Kjeld Nielsen ${ }^{[0000-0002-3720-167 X]}$, and Xavier Delorme ${ }^{1[0000-}$ \\ 0002-9465-1255] \\ ${ }^{1}$ Mines Saint-Etienne, Univ Clermont Auvergne, CNRS, UMR 6158 LIMOS, Institut Henri \\ Fayol, 42023 Saint- Etienne, France \\ ${ }^{2}$ Department of Materials and Production, Aalborg University, Aalborg, Denmark \\ Omar.ezzateemse.fr
}

\begin{abstract}
.
Many manufacturers are in the process of evolving from mass production to mass customization to cope with the increasing diversity of customer requirements. This induces an increasing complexity resulting from the high variety offered to customers. This problem is heightened by integrating product and service within the same offering. Modularity is considered as a driver for reducing complexity while increasing offered variety of products and services. This paper addresses the question of how to modularize products and/or services considering different criteria from the designers and domain experts. To this end, a Design Structure Matrix (DSM) based method is introduced. The method relies on a set of modularization criteria and on clustering to form product and/or service modules. The applicability of the method is illustrated through a test case in the manufacturing sector.
\end{abstract}

Keywords: Product Modularity, Service Modularity, Clustering, Design Structure Matrix, Variety management.

\section{Introduction}

Implementing Mass customization (MC) has several benefits but also comes with several challenges, such as the increased internal complexity resulting from offering high variety for different customers. Several researches have focused on how to decrease this complexity while keeping a reasonable level of offering variety [1]. The principle of modularity a promising means to meet this objective [2]. Modularity ensures reuse of components implying faster response with fewer resources. This helps in providing efficiently tailor made offer to customer [2]. Modularity has been widely used in product design and to some respect in process design [3]. More recent research works have shown that this concept started to gain more interest in the service engineering domain [4-6]. This article focuses specifically on a method for modularizing products and/or 
services. The aim is generate offering variety in a standardized way of forming modules. Design Structure Matrix (DSM) is used as a tool to evaluate the products and/or services interrelationships using several predefined criteria. A hierarchal clustering algorithm is used to form modules based on the similarity criteria. Unlike the traditional methods focusing on product or service separately, the proposed method suggests that similarity is studied also between products and services. This allows for easing the management of the products and services operations during subsequent use phase and is likely to generate potential economies of scales.

The remainder of this paper is structured as follows: Section 2 provides a brief overview of modularity, clustering and clustering evaluation. Section 3 describes the general steps of the methodology. Section 4 focuses on an illustrative test case. Section 5 provides concluding remarks and discusses research perspectives.

\section{$2 \quad$ Literature Review}

This section provides a brief review of the literature on modularity and on clustering. The objective is to gain some insights into whether existing approaches can be adapted to the context of the current research. A major challenge in MC companies that needs to be dealt with is the internal complexity coming from product or service variety. Such complexity is heightened when considering product and service jointly in the offering [7]. Nowadays a key to address these challenges is modularity which is a means for enhancing flexibility and increasing variety [8]. While much research was concerned by either product modularity and to some extent service modularity, little research has focused on applying modularity to a mix of products and services [6]. [9] provided a modularization method of Product Service System (PSS) based on the functional requirement and by using fuzzy clustering algorithm. [10] focused on the relationship between service and product and how they can cope with the customer service and physical needs. Modularization have been coupled with several methods and tools, such as DSM.

DSM is used for modelling and structuring relationships between elements that are part of a complex system [11]. DSM provides a valuable input for the clustering process. This latter relies on several algorithms such as hierarchal clustering and k-means [12]. Algorithms falling under hierarchal clustering category group the elements following a hierarchal procedure. Each element is assigned to a given group (starting with a one object group comprised by the element itself) after which the algorithm iteratively joins the two most similar elements into one cluster. The process continues this way until there is just one big cluster with all the elements [13]. Dendrograms are used to illustrate the results showing the modules. Clustering can then be evaluated using several metrics. [14] provided an evaluation comparison between several clustering method using minimum description length (MDL) which refers to the assignment of elements to a cluster. [15] developed a metric that measures the intra and inter module connectivity in a modularity matrix. Evaluating clustering results provides valuable support for choosing the best way of modularizing the offering consisting of products and services. 
While some methods are available in the literature, they have mostly been applied to product domains and to some extent service domain. Next section introduces a holistic method for modularizing products and/or service.

\section{Proposed method}

The key phases of the proposed method are data preparation and clustering. Data preparation consists of identifying products and/or services and on building the DSM. This is a preparatory phase aiming at $i$ ) identifying the granularity level of existing products and/or services, which are included in the offering and ii) building the DSM based on gathered data [5]. The focus of the subsequent sections will be on building the DSM and the clustering process, respectively.

\subsection{Building DSM}

Building up the similarity relationship of products and/or services will result in forming the integrated modules. Building DSM is detailed into five steps as shown in Figure 1.

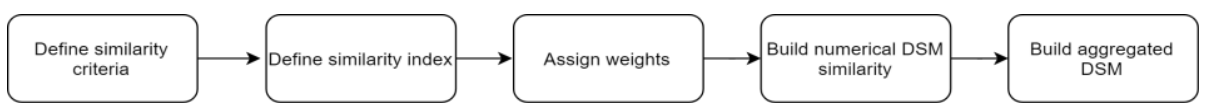

Fig. 1. Detailed steps for building DSM

Define similarity criteria. The first step is to define the needed criteria that will result in finding similarities between the elements (product and/or services components). Due to the complexity of similarity evaluation, it is necessary first to identify appropriate criteria for assessing such similarity. A set of generic criteria have been identified as candidates for this step:

- Functional requirements: refers to which extent given elements contribute to fulfilling the same functional requirement. The resulting similarity can be assessed by customers and design engineers [9].

- Commonality: measures the simultaneous occurrence of given elements in different products and/or services [4].

- Human resources: refers to whether two elements are supported by the same resource. For example, a multi-skilled engineer can be a common resource in two elements that will result in a similarity relationship.

- Technological information: refers to whether two elements rely on the same tools (hardware or software) or share certain information.

Define similarity index. Based on the defined similarity criteria, the elements' interrelationships are evaluated through experts' judgement resulting in the assignment of similarity indices to these relationships. The value of each similarity index ranges from 
0 to 3 . A complete similarity receives an index of 3 and 0 is given if there is no similarity. 1 is assigned for weak similarity and 2 is assigned for intermediate similarity.

Assign weights. A weight is computed for each of the predefined criteria based on experts' judgment. The weight of a criterion reflects its relative importance, the nearer it is to 1 the more important this criterion is. The sum of the weights of the indices has to be equal to 1 (see Eq. 1).

$$
\sum_{k=1}^{n} w_{k}=1
$$

Where $w_{k}$ is the weight assigned to the $k$ th similarity criteria and $n$ is the total number of predefined criteria.

Build numerical DSM. DSM is used to visualize and document the similarity indices. Each (product or service) element is represented by one DSM coefficient. A DSMc will be built for each criterion $c$.

Build aggregated DSM. An aggregated matrix $A$ will be generated based on the DSM $c$. The coefficients of $A$ denoted $c_{i j}^{\mathrm{A}}$ results from the weighted sum of the ones in step 3 from the initial matrices, denoted $\mathrm{c}_{\mathrm{ij}}^{\mathrm{k}}$. For $n$ criteria, the coefficients of $A$ are calculated according to Eq. 2.

$$
c_{i j}^{A}=\sum_{k=1}^{n} c_{i j}^{k} \times w_{k}
$$

\subsection{Cluster aggregated DSM}

The $A$ matrix is the starting point for the clustering. Hierarchal clustering was chosen for realizing the clustering at this point as it is considered one of the most used algorithms in the area of data mining [13]. First, the distance between two elements in the aggregated DSM is calculated by using the Euclidian distance, based on their coefficients in $A$, these results in a distance matrix. The elements with the shortest distance are grouped together first forming an initial cluster. Afterwards, the value of the distance matrix of these two elements is averaged and a new distance matrix is generated. This process continues until all the elements are grouped together into one big cluster. Complementarily, a dendrogram can be used to provide a visual illustration of the hierarchal clustering. A cutting level can be defined according to the expected clustering quality, to derive the clustered modules. The lower the level the higher the number of clustered modules. Depending on the acceptable quality level by the decision makers, several alternative clusters could be identified through the cutting level.

\subsection{Clustering evaluation}

Several alternative modularization scenarios could be considered out of the clustering process. It is either because of the defining criteria or weight assignment or as well the 
clustering method. Therefore an evaluation of these alternative scenarios is required to decide which one is the most appropriate. Several modularity indices have been proposed to evaluate the performance of the clustering. One basic evaluation consists in measuring the number of the clustered modules. Another one is to measure the connectivity of inter and intra module of the modularity matrix [15].

\section{$4 \quad$ Illustrative test case}

This section briefly illustrates the proposed method with particular focus on building the DSM and deriving the modules. The target company is a supplier to the wind turbine industry that offers a high variety of services to the customers. In this example, the service 'transport booking' with four different variants is used in the method. Modularization of the services is offered by the company to enhance the flexibility and be able to offer new customized offering without designing a service from scratch. The DSM inputs are the activities of the customized service and the outputs are the modules of those activities to form the required services.

\subsection{Building DSM}

The input data for building the DSM are four service blueprints that define the service process for each of the offered service variants. Each service blueprint includes information about activities, resources, technological information and materials. The service blueprints have been analyzed to extract the required information for building the interrelationships.

Define relationship criteria. Analyzing the data from the blueprints helps in identifying the four criteria to build up the similarity depending on them. All four criteria (functional requirement, commonality, human resources and technical information) that were described in section 3.1 can be used based on the analysis of the blueprints. An example for the functional requirement criteria is "checking whether information is correct" as several activities are done with the purpose of validating the information. As well, several activities share the same purpose of the functional requirement "create the reservation on customer portal system", meaning that these could be potentially grouped in one module. The HR resources in the data gathered are logistics representative and warehouse operator. The similarity here refers to which extent do the activities share each of the above resources. This principle applies also to the technical information criterion.

Define similarity index. The activities and criteria are given to a group of experts and managers to assign the similarity indices. They have background about the case specific information as well as industrial engineering and engineering design at large. The interrelationships are assigned indices between 0 and 3 based on each criterion. For ex- 
ample, both activities "insert pallet with unique reference number" and "Upload delivery note to booking" share the same technical material and the needed information that are the customer's transport management system and the computer. Therefore, the similarity is high and the corresponding index is estimated to 3. On the other hand, the activities "insert pallet with unique reference number" and "print CMR papers" share just 1 out of 3 material and information that is the computer. Because of that, the similarity between them in technology information criterion is weak so they will have 1 as a similarity index.

Assign weights. Based on Eq.1, the sum of all weights should equal 1. Based on the experts' points of view, all the criteria should have equal weights. Therefore, all of them will have a weight of 0.25 .

Build numerical DSM. Four numerical DSMs are formed representing the similarity indices of each the four criteria. An excerpt of the functional requirement DSM is shown in Table 1. Because of the space limit, the full DSM will not be detailed.

Build Aggregated DSM. The aggregated matrix 'A' shown in Table 1. By using the data from previous step and applying the weight indices of 0.25 to each criteria, the coefficient between the two activities 'print CMR papers' (A33) and 'upload delivery note to booking' (A31) for the aggregated matrix will be (based on Eq.2):

$$
c_{3133}^{A}=0 \times 0.25+1 \times 0.25+3 \times 0.25+1 \times 0.25=1.25
$$

Table 1. Part of the functional criterion DSM and the aggregated DSM

\begin{tabular}{|c|c|c|c|c|c|c|c|c|}
\hline & \multicolumn{3}{|c|}{ Functional requirement DSM } & \multicolumn{4}{|c|}{ Aggregated DSM } \\
\hline A & A30 & A31 & A32 & A33 & A30 & A31 & A32 & A33 \\
\hline A30 & 3 & 2 & 3 & 0 & 3 & 2.25 & 2.5 & 1.25 \\
\hline A31 & 2 & 3 & 2 & 0 & 2.25 & 3 & 2.25 & 1.25 \\
\hline A32 & 3 & 2 & 3 & 0 & 2.5 & 2.25 & 3 & 1.25 \\
\hline A33 & 0 & 0 & 0 & 3 & 1.25 & 1.25 & 1.25 & 3 \\
\hline
\end{tabular}

\subsection{Cluster aggregated DSM}

The aggregated matrix $A$ will be rearranged to form the initial clusters of service activities that can form the modules. Hierarchal clustering was applied at this point. A dendrogram is used to represent the clustering results (Figure 2). Several scenarios of forming clusters can be done. One effective factor is the cutting level for the dendrogram plot. With a cutting level at 5 (height in the dendogram), the activities A11, A12, A13 and A14 are combined in a single module (module 1). By analyzing the modules, it can be seen that module 1 is related to loading the cargo. Clearly, the final decision on the cutting level pertains to the practitioner who can evaluate properly the tradeoffs between clustering quality and implications to the design and operations. 

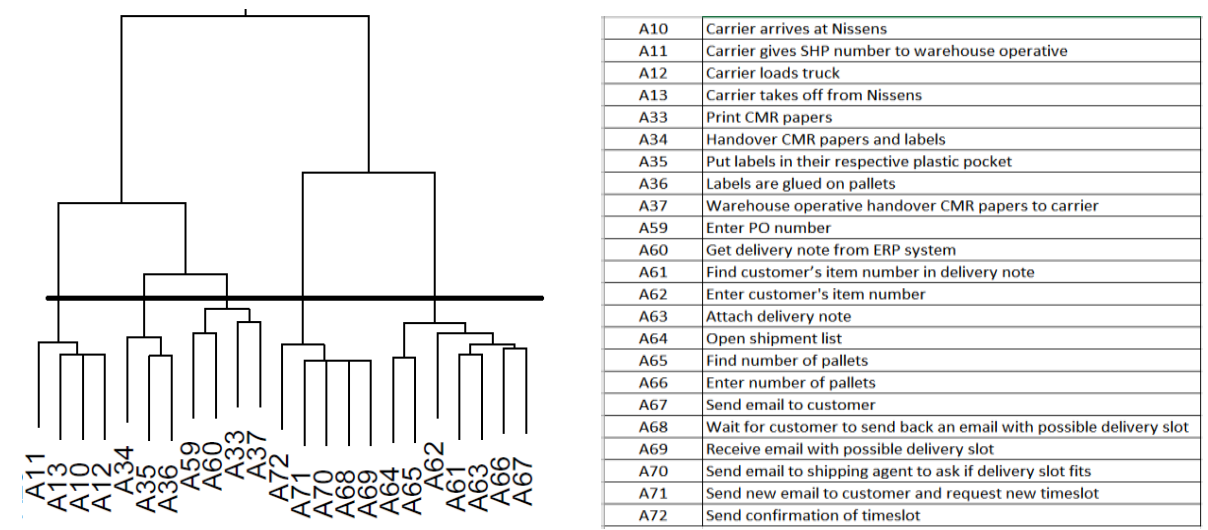

Fig.2. Part of the Dendrogram for the hierarchal clustering with activities

\section{Discussion}

An illustrative case study of service modularization of a company was addressed. For this case, all the criteria were important to be defined. The method was found effective for service modularization as it brings out modules in a standardized manner. Therefore, it can help in faster design and in more agility against requirement changes. While the test case is a service company, the proposed method can still be applied to product and/or service modularization. For other cases that can be pure product or integration of product and service, the defined criteria can be changed but it will not affect the method as much as it affects the grouping of the elements into modules. Therefore, it is necessary to analyze the criteria that will build up the similarity interrelationships. Therefore, defining the criteria needed is based on the expert's point of view. One other factor that affects the number of output modules is the cutting level for the dendrogarm of hierarchal clustering. Another factor that can affect the output modules is the similarity indices and the weight assignment for building the aggregated DSM matrix. A promising research perspective is how to find the most appropriate modularity scenarios based on a combination of the above factors. Modularizing the offer is likely to reinforce the economies of scales of the company and as well increase the flexibility that will enhance directly the idea of mass customization of product and/or service.

\section{Conclusion}

This paper proposes a new method for modularizing products and/or services. The idea of the method is to be workable for applying it on product and/or service. The method helps in building similarity relationships between products and/or services according to several predefined different criteria. Clustering using hierarchal algorithm was pro- 
posed and supports the idea of forming modules through identifying similarity relationships. Evaluating the performance supports the comparison of different modularity scenarios, which will have a valuable support for decision makers of variety management.

\section{References}

1. Daniilidis, C., Enßlin, V., Eben, K., Lindemann, U.: A classification framework for product modularization methods. In: Culley, S.J., Hicks, B.J., McAloone, T.C., Howard, T.J., Lindemann,U. (eds.) ICED 2011, vol. 4, pp. 400-409, Lyngby/Copenhagen (2011).

2. Hvam, L., Herbert-Hansen, Z. N. L., Haug, A., Kudsk, A., Mortensen, N. H.: A framework for determining product modularity levels. Advances in Mechanical Engineering 9(10), 1 14 (2017).

3. Vickery, SK., Dro C., Calantone R.: Product Modularity, Process Modularity , and New Product Introduction Performance: Does Complexity Matter?. Prod Oper Manag 25(4), 751-770 (2016).

4. Medini, K., Moujahid, A., Boucher, X., Bernard, A.: Product and Service Variety Versus Internal Performance: Toward New Balances. In: Hankammer, S., Nielsen, K., Piller, F., Schuh, G., Wang, N. (eds.) MCPC 2017, pp. 581-594. Springer, Cham (2018)

5. Ezzat, O., Medini, K., Boucher, X., Delorme, X.: Product and service modularization for vaiety management. In: Da Chuna, C., Bernard, A., Zah, A., ElMaraghy, H., ElMaraghy,W.(eds.) CARV 2018, Procedia Manuf vol. 28 pp. 148-153. (2019)

6. Larsen M.S.S., Andersen AL., Nielsen K., Brunoe T.D.: Modularity in Product-Service Systems: Literature Review and Future Research Directions. In: Moon I., Lee G., Park J., Kiritsis D., von Cieminski G. (eds.) Advances in Production Management Systems, Production Management for Data-Driven, Intelligent, Collaborative, and Sustainable Manufacturing. APMS 2018. IFIP Advances in Information and Communication Technology, vol 535. pp 150-158. Springer, Cham (2018).

7. Wang, P.P., Ming, X.G., Li, D., Kong, F.B., Wang, L., Wu, Z.Y.: Modular Development of Product Service, Concurrent Engineering. 19(1), 85-96 (2011).

8. Medini, K., Da Cunha, C., Bernard, A.: Tailoring performance evaluation to specific industrial contexts - application to sustainable mass customisation enterprises. Int J Prod Res 52(8), 2439-2456 (2015).

9. Sun, J., Chai, N., Pi, G., Zhang, Z., Fan, B.: Modularization of product service system based on functional requirement. IPSS 2017, Procedia CIRP vol. 64, pp.301-305 (2017).

10. Li, H., Ji, Y., Gu, X., Qi, G., Tang, R.: Module partition process model and method of integrated service product. Comput Ind. 63(4), 298-308 (2012).

11. Sakao, T., Song, W., Matschewsky, J.: Creating service modules for customising product/service systems by extending DSM. CIRP Ann - Manuf Technol. 66(1), 21-24 (2017).

12. Qiao, L., Efatmaneshnik, M., Ryan, M., Shoval, S., Efatmaneshnik, M., Ryan, M.: Product modular analysis with design structure matrix using a hybrid approach based on MDS and clustering. J Eng Des 28(3), 1-24 (2017).

13. Kaur, M., Kaur, U.: Comparison Between K-Mean and Hierarchical Algorithm Using Query Redirection. Int J Adv Res Comput Sci Softw Eng 3(7), 1454-1459 (2013).

14. Yu, TL., Yassine, A.A., Goldberg, D.E.: An information theoretic method for developing modular architectures using genetic algorithms, Res. Eng. Des. 18(2), 91-109 (2007).

15. Gershenson, JK., Prasad, GJ., Zhang, Y.: Product modularity: Measures and design methods. J Eng Des 15(1), 33-51 (2004). 